\title{
Locomotive syndrome: a important condition in the aging
}

\begin{abstract}
This mini review discusses the definition, burden, diagnosis and management pertaining to important condition in the aging, the locomotive syndrome (Slo). Concept and measures should be spreading throughout the professionals who take care of elderly people around the world.
\end{abstract}

Keywords: elderly, locomotive syndrome
Volume I Issue 4 - 2017

\section{Fania Cristina dS, Daniela Regina BT}

Department of Service of Pain and Osteoarticular Diseases,

Federal University of São Paulo, Brazil

Correspondence: Fania Cristina dS, Department of Service of Pain and Osteoarticular Diseases of the Discipline Geriatrics and Gerontology, Federal University of São Paulo, Brazil,Tel I I55732084,Email faniacs@uol.com.br

Received: May 23, 2017 | Published: June 05, 2017

\section{Introduction}

The growth of the elderly population is a worldwide phenomenon and, in Brazil, the changes occur in a radical and quite accelerated way. Life expectancy increased from 48 years in 1960 to 73.4 years in 2010. Over the same period, the number of elderly people increased from 3.3 million ( $4.7 \%$ of the population) to 20.5 million $(10.8 \%$ of the population). ${ }^{1}$ This process has an important impact on public health and repercussions for society as a whole, especially in a context of fragility of institutions. ${ }^{2}$

Most of the health problems faced by older people are associated with chronic conditions, mainly non-communicable diseases. ${ }^{3}$ Among these conditions, chronic-degenerative diseases, especially those of articular origin, are common in this age group and require greater care and constant monitoring, requiring adequacy of geriatric assessment, with the adoption of well-established routines for this group. ${ }^{4}$ The locomotive system, which consists of the integration of the bone part, joints, muscles and nerves, is fundamental in maintaining the quality of life of the elderly because its function directly affects the basic activities of daily life of this population. Injury to these organs causes pain, limitation of movement, muscle weakness and balance disorder. ${ }^{5-7}$

In this context, The Japanese Orthopedic Association proposed in 2007 the term Locomotive Syndrome (Slo) in order to identify a condition with reduced mobility or risk of developing such a condition, due to the impairment of one or more groups of the locomotive system and, thus, to predict a greater need for nursing care and loss of functionality. ${ }^{8}$ Several diseases seem to contribute to, or be associated with, Slo, such as lumbar, hip and knee osteoarthritis, spinal canal stenosis and osteoporosis. ${ }^{9}$

The early recognition of locomotive syndrome (Slo) is extremely important for therapeutic measures to be adopted in order to improve mobility and, thus, preserve the functional independence of individuals.

\section{Diagnosis and management}

For its diagnosis, the GLFS-25 instrument was created "25-question Geriatric Locomotive Function Scale", in Japan, which has recently been translated and adapted to the Portuguese language in Brazil. Simple and common alarm signals help to suspect Slo and can be seen in elderly people who have difficulty walking, climbing stairs or doing housework in their home. As mentioned, they have a significantly higher risk of needing nursing care, having falls, fractures and functional dependence when compared to those who do not have such difficulties. ${ }^{10,11}$

The JOA (Japanese Orthopedic Association) created "Lococheck" in 2007, a questionnaire consisting of 7 questions that allows rapid screening of people who are at high risk of developing Slo. This instrument can be applied by the patient in order that whoever gets an affirmative answer to any of the questions has a positive screening and should be further investigated for this (Table 1$).{ }^{12}$

Table I Loco-check

I Can you put your sock on standing on one leg?

2 Do you often trip up or slip around the house?

3 Do you need to hold on to the handrail when climbing the stairs?

4 Do you have difficulty to do moderately heavy housework?

5 Do you have difficulty to carry home $2 \mathrm{Kg}$ of shopping?

6 Can you walk for a quarter of an hour nonstop?

7 Can you make it across the road before the light turns red?

GLFS-25 is a self-administered, multidimensional questionnaire composed of 4 questions related to pain, 16 related to daily living activities, 3 that address social aspects and 2 about mental health. This questionnaire was validated for the Japanese language by Seichi et al. ${ }^{10}$ who suggested the cut-off point of 16 in order to define Slo. ${ }^{10}$ Later, in 2015, the translation, cross-cultural adaptation and validation for the Portuguese language of Brazil was performed, giving rise to GLFS 25-P (Geriatric Locomotive Function Scale of 25 items). ${ }^{11}$ Each item is graded from 0 to 4 , generating a maximum final score of 100 , with the higher the value obtained, the greater the impairment.

Maintaining the integrity of the locomotive system is fundamental in preventing disability in the elderly patient. Lifestyle, in turn, has a considerable influence on the health of bones, muscles and joints. The practice of regular physical activity throughout life favors the maintenance of muscular strength and balance. Healthy and balanced eating prevents obesity, which, in turn, would overload the joints. 
Additionally, chronic pain and diseases affecting the locomotive system, such as osteoarthritis and osteoporosis, must be evaluated and treated..$^{13}$

Finally, to widespread among the elderlies at risk of impairment of locomotive organs and also to make health professionals aware of importance to recognized that problems, comprehensive concepts and assessment methods should be implemented, which needed to be accessible, feasible, and subject to easy interpretation management. ${ }^{7}$ The introduction of concepts of locomotions dysfunctions assist the prevention of care-need condition. ${ }^{14}$

\section{Concluding remarks}

The Slo is closely related to different aspects of aging, from a very successful process to aging with fragility. And, despite the relevance, there is still a shortage of research on the subject. The health professional who deals with the geriatric patient should be trained to approach and manage, precociously, the problems related to locomotion. It is necessary to monitor the health problems of the elderly and prevent Slo, for the maintenance of functional capacity and autonomy during the course of life of the elderly.

\section{Acknowledgements}

None.

\section{Conflict of interest}

Author declares there is no conflict of interest in publishing the article

\section{References}

1. http://biblioteca.ibge.gov.br/visualizacao/livros/liv93322.pdf

2. Chaimowicz F, Camargo MCS. Epidemiologia e o envelhecimento no Brasil. In: Freitas EV, Py L, editor. Tratado de Geriatria e Gerontologia. 2nd ed. Rio de Janeiro: Guanabara Koogan. Brazil; 2006. p. 106-130.

3. http://sbgg.org.br/wp-content/uploads/2015/10/OMSENVELHECIMENTO-2015-port.pdf
4. Sasaki E, Ishibashi Y, Tsuda E, et al. Evaluation of locomotive disability using loco-check: a cross-sectional study in the Japanese general population. J Orthop SciJan. 2013;18(1):121-129.

5. Ebrahim S, Wannamethee SG, Whincup P, et al. Locomotor disability in a cohort of British men: the impact of lifestyle and disease. Int $J$ Epidemiol. 2000;29(3):478-486.

6. Muller S, Thomas E, Peat G. The effect of changes in lower limb pain on the rate of progression of locomotor disability in middle and old age: evidence from the NorStOP cohort with 6-year follow-up. Pain. 2012;153(5):952-959.

7. Nakamura K, Ogata T. Locomotive Syndrome: Definition and Management. Clinic Rev Bone Miner Metab. 2016;14(2):56-67.

8. Nakamura K. The concept and treatment of locomotive syndrome: its acceptance and spread in Japan. J Orthop Sci. 2011;16(5):489-491.

9. Hirano K, Imagama S, Hasegawa Y, et al. The influence of locomotive syndrome on health-related quality of life in a community-living population. Mod Rheumatol. 2013;23(5):939-944.

10. Seichi A, Hoshino Y, Doi T, et al. Development of a screening tool for risk of locomotive syndrome in the elderly: the 25-question Geriatric Locomotive Function Scale. J Orthop Sci. 2012;17(2):163-172.

11. Tavares DR, Santos FC. Locomotive syndrome in the elderly: translation, cultural adaptation, and Brazilian validation of the tool 25-Question Geriatric Locomotive Function Scale. Rev Bras Reumatol. 2016;57(1):56-63.

12. Okubo T, Suehara Y, Kawasaki T, et al. An Outpatient-based Survey about the Recognition of Locomotive Syndrome and the Results of the Loco-check at a University Hospital in Tokyo. Br J Med Med Res. 2014;4(17):3255-3268.

13. Branch LG1, Guralnik JM, Foley DJ, et al. Active life expectancy for 10,000 Caucasian men and women in three communities.J Gerontol. 1991;46(4):145-150.

14. Akai M, Doi T, Seichi A, et al. Locomotive Syndrome: Operational Definition Basedon a Questionnaire, and Exercise Interventions on MobilityDysfunction in Elderly People. Clinic Rev Bone Miner Metab. 2016;14:119-130. 